\title{
Performance of microscopy and ELISA for diagnosing Giardia duodenalis infection in different pediatric groups
}

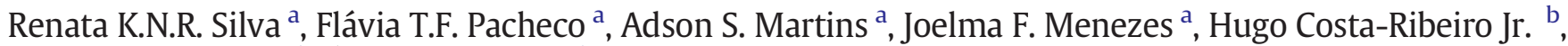 \\ Tereza C.M. Ribeiro ${ }^{\mathrm{b}}$, Ângela P. Mattos ${ }^{\mathrm{b}}$, Ricardo R. Oliveira ${ }^{\mathrm{c}}$, Neci M. Soares ${ }^{\mathrm{a}}$, Márcia C.A. Teixeira ${ }^{\mathrm{a}, *}$ \\ a Faculdade de Farmácia, Universidade Federal da Bahia, Salvador, Brazil \\ b Centro Pediátrico Professor Hosannah de Oliveira, Universidade Federal da Bahia, Salvador, Brazil \\ c Centro de Pesquisas Professor Gonçalo Moniz, Fundação Oswaldo Cruz, Salvador, Brazil
}

\section{A R T I C L E I N F O}

\section{Article history:}

Received 27 February 2015

Received in revised form 24 July 2016

Accepted 29 August 2016

Available online 30 August 2016

\section{Keywords:}

Giardia duodenalis

Children

Diagnosis

ELISA

Microscopy

PCR

\begin{abstract}
A B S T R A C T
Techniques for Giardia diagnosis based on microscopy are usually applied as routine laboratory testing; however, they typically exhibit low sensitivity. This study aimed to evaluate Giardia duodenalis and other intestinal parasitic infections in different pediatric groups, with an emphasis on the comparison of Giardia diagnostic techniques. Feces from 824 children from different groups (diarrheic, malnourished, with cancer and from day care) were examined by microscopy and ELISA for Giardia, Cryptosporidium sp. and Entamoeba histolytica coproantigen detection. Giardia-positive samples from day-care children, identified by either microscopy or ELISA, were further tested by PCR targeting of the $\beta$-giardin and $G d h$ genes. Statistically significant differences $(P<0.05)$ were observed when comparing the frequency of each protozoan among the groups. Giardia duodenalis was more frequent in day-care children and Cryptosporidium sp. in diarrheic and malnourished groups; infections by Entamoeba histolytica were found only in children with diarrhea. Considering positivity for Giardia by at least one method, ELISA was found to be more sensitive than microscopy (97\% versus 55\%). To examine discrepancies among the diagnostic methods, 71 Giardia-positive stool samples from day-care children were tested by PCR; of these, DNA was amplified from 51 samples (77.4\%). Concordance of positivity between microscopy and ELISA was found for 48 samples, with 43 confirmed by PCR. Parasite DNA was amplified from eleven of the 20 Giardia samples (55\%) identified only by ELISA. This study shows the higher sensitivity of ELISA over microscopy for Giardia diagnosis when a single sample is analyzed and emphasizes the need for methods based on coproantigen detection to identify this parasite in diarrheic fecal samples.
\end{abstract}

(c) 2016 Elsevier Ireland Ltd. All rights reserved.

\section{Introduction}

Children are an important risk group for enteroparasitic diseases, both because their immune system is not fully developed at the first contact with the parasite or because of the habits of infants, such as bringing any object to the mouth or having increased contact with the ground [1]. Moreover, regardless of the integrity of the immune response, chronic infections with intestinal parasites in children can lead to malnutrition, anemia, and growth delay [2].

Giardiasis has a global distribution, and Giardia is one of the most common parasites associated with diarrhea in humans. Due to the high prevalence of giardiasis in young children in developing countries and its effects on early childhood diarrhea and malnutrition, giardiasis is of considerable public-health importance [1-3]. In 2004, Giardia duodenalis,

* Corresponding author at: Faculdade de Farmácia, Universidade Federal da Bahia, Salvador, Bahia 40170-115, Brazil.

E-mail address: marciat@ufba.br (M.C.A. Teixeira). along with Cryptosporidium sp., was included in the "Neglected Diseases Initiative" group of the World Health Organization [4]. The transmission of giardiasis occurs via a fecal-oral route, with infection resulting from the ingestion of cysts present in food or water contaminated with feces [5]. Direct transmission from person to person also contributes to the dissemination of the parasite among children attending day-care centers and schools $[1,5,6]$.

Giardia trophozoites are identified through direct examination of diarrheal stools, whereas the detection of cysts is optimized by concentration methods, such as centrifugal flotation [7] or sedimentation by centrifugation [8]. After concentration, fecal smears can be stained using iodine or iron hematoxylin [9], and microscopy has certain advantages, such as the possibility of simultaneous detection of several parasites, low cost, and ease of implementation [10]. However, due to the intermittency of cyst excretion in feces, the examination of multiple samples is necessary to increase the efficiency of parasitological diagnosis $[11,12]$.

Immunoassays for Giardia antigen detection have been used as alternative methods for the diagnosis of giardiasis, and these methods 
present high sensitivity and specificity $[13,14]$. However, the routine use of these kits in the laboratory is controversial due to the high cost in relation to stool examination by microscopy.

Molecular techniques based on the amplification of parasite DNA have emerged and include the polymerase chain reaction (PCR), which has been shown to be a highly sensitive and specific method that allows the detection of Giardia DNA directly from fecal samples [15-17]. Nevertheless, a negative result does not rule out the presence of the parasite because interference from PCR inhibitors present in feces may hamper DNA amplification.

The objective of this study was to determine the frequency of Giardia duodenalis infection and other intestinal parasites in different pediatric groups with and without health issues and to compare the performance of ELISA and microscopy for G. duodenalis diagnosis.

\section{Materials and methods}

\subsection{Samples}

Stool samples were obtained from 824 children, divided into the following groups: cancer $(n=70)$; malnourished $(n=110)$; diarrheal disease $(n=151)$; and attending day care centers $(n=493)$. Sample size for this study was determined using Epi Info software. As the main goal was to compare techniques for Giardia diagnosis in different groups, it was taking into account previous studies of giardiasis in pediatric population with similar characteristics. Therefore, the expected prevalence of Giardia duodenalis infections were considered to be approximately $6.0 \%$ for cancer [18], $10.0 \%$ for malnourished [19] $4.7 \%$ for diarrheic [20] and $22.1 \%$ for day-care children [21-23]. Considering a $90 \%$ confidence interval, the minimal sample size determined for the groups studied were $62,98,49$ and 187 , respectively. Thereafter, all children whose parents accepted to participate of the study and signed an informed consent were enrolled during the research period.

All children fitted to general inclusion criteria such: aged under 10 years, users of health public services, from low-income families (one Brazilian minimum salary or less) and whose parents or guardians agreed to participate and signed an informed consent form. Specific inclusion criteria for groups included: a) Cancer - pediatric patients with confirmed neoplastic disease; b) Malnourished - children with diagnosis of severe protein-energy malnutrition, associated to poor diet; c) Diarrheic - patients with acute or persistent diarrhea, with signs of dehydration; d) Day care children - apparently healthy children without any infection/pathology diagnosed. Therefore, for children with healthy issues, the most important inclusion criteria was to have confirmed diagnosis of the base disease by medical practitioners, including pediatricians and/or specialists, such oncologists.

The majority of participants were composed of young children (up to 5 years) in cancer $(45 / 70 ; 64.3 \%)$, malnourished (98/110; $89.1 \%)$, diarrhea $(133 / 151 ; 88.1 \%)$ and in day-care $(493 / 493 ; 100 \%)$ groups. Children hospitalized at the Hospital of Federal University of Bahia, Brazil, comprised the malnutrition and diarrheic pediatric groups. Children with cancer were outpatients of the same hospital, assisted by ambulatory or laboratory services. Of the 70 children with neoplastic diseases, 40 (57.1\%) had acute lymphocytic leukemia or myelogenous leukemia, whereas $12(17.1 \%)$ had malignant brain tumors and 9 (12.9\%) lymphoma. The 9 (12.9\%) remaining patients included children with retinoblastoma, abdominal neuroblastoma and thyroid carcinoma. Apparently healthy children without any infection/pathology diagnosed were recruited from two day care centers located in the same city district and supported by a social institution.

The study was conducted from January 2011 to June 2012. One single stool specimen was collected from each child and immediately transported to the Parasitology Laboratory of Pharmacy Faculty of Federal University of Bahia for processing. This study was approved by the Ethics Committee of the Department of Health of Bahia, and all parasitological test results were sent to the children's parents or the respective pediatrician or oncologist. Individuals found positive for pathogenic intestinal parasites were treated with appropriate drugs by their doctors.

\subsection{Diagnosis of intestinal parasites in fecal samples}

Stool samples from malnourished, cancer and day-care children were mostly formed or soft and were subjected to six parasitological methods: a) direct examination; b) the Baermann-Moraes technique [24]; c) stool culture on agar plate [25]; d) zinc sulfate (density of solution $1.18 \mathrm{~g} / \mathrm{ml}$ ) centrifugal flotation [7]; e) sedimentation by centrifugation in water [8] and f) modified Ziehl-Neelsen staining [26]. Diarrheal stool samples were examined by all methods cited above, except for the Baermann-Moraes method due to well-known technical limitations for liquid stools.

Fecal pellets obtained by the sedimentation technique were tested for helminths and protozoa by wet mounts with saline and iodine, as well as staining with modified Ziehl-Neelsen for Cryptosporidium microscopical diagnosis. Two slides were examined for each technique. Besides the parasitological examination, all samples from the four groups of children were tested by ELISA for coproantigen detection of Giardia duodenalis, Cryptosporidium sp., and Entamoeba histolytica (Wampole II Cryptosporidium, Giardia II, and E. histolytica II, TECHLAB, Blacksburg, VA, USA), except for 12 samples from the malnourished and 16 from the diarrheic children due to insufficient sample.

\subsection{Comparison between ELISA and microscopy for the diagnosis of Giardia duodenalis in fecal samples}

Considering the irregular fecal cyst excretion in asymptomatic hosts and the reduced viability of trophozoites in diarrheal specimens, the use of different diagnostic methods is necessary to increase the sensitivity of parasite identification in fecal samples. In this study, the diagnosis of $G$. duodenalis in fecal samples was performed by microscopy - through direct examination, centrifugal sedimentation and flotation in zinc sulfate - and by ELISA for Giardia coproantigen.

For a comparison analysis between $G$. duodenalis diagnosis by ELISA and microscopy, only 796 fecal samples were tested due to a lack of sufficient material for 12 samples from the malnourished children and 16 from the group with diarrhea. The sensitivity, specificity, positive predictive value (PPV), negative predictive value (NPV), and accuracy kappa coefficient were evaluated by two different approaches, as follows: a) evaluation of ELISA considering microscopy as the gold standard and b) evaluation of microscopy and ELISA considering the combined results of all methods tested.

\subsection{Assessment of discrepancy between microscopy and ELISA results using} PCR for G. duodenalis identification in feces

Seventy-one G. duodenalis-positive stool samples from day-care children diagnosed by microscopic and/or ELISA, as described above, were subjected to PCR to evaluate discordant results between the diagnostic methods. Of these, 3 samples were identified only by microscopy, 20 exclusively by ELISA, and 48 by both methods. Giardia PCR was conducted only with samples from the day-care children because this group provided most of the positive samples (134/152) as well as sufficient stool for DNA extraction.

DNA from G. duodenalis cysts was purified using QIAamp DNA Stool Mini Kit (Qiagen, Hilden, Germany) according to the manufacturer's instructions, with some modifications. For example, the time and temperature of the cell lysis step were increased to $10 \mathrm{~min}$ at $95^{\circ} \mathrm{C}$, and the DNA elution volume was reduced to $100 \mu \mathrm{l}$ of buffer.

A 753-bp fragment of the $\beta$-giardin gene was amplified using forward primer G7 and reverse primer G759, as described by Cacciò et al. [27]. In the sequential nested PCR reaction, a 511-bp fragment was amplified using forward primer G99 and reverse primer G609, as described 
by Lalle et al. [28]. In all cases, the PCR mixture consisted of $1 \times$ buffer containing $1.5 \mathrm{mM} \mathrm{MgCl}_{2}, 200 \mu \mathrm{M}$ of each dNTP, $10 \mathrm{pmol}$ of each primer, 2.5 units of Taq DNA polymerase (Invitrogen), and $1 \mu$ of purified DNA in a final volume of $25 \mu$. The PCR reactions were performed as follows: an initial denaturation step of $5 \mathrm{~min}$ at $94^{\circ} \mathrm{C}$ for the first PCR and $15 \mathrm{~min}$ at $95^{\circ} \mathrm{C}$ for the nested-PCR, followed by 35 cycles of $30 \mathrm{~s}$ at $94{ }^{\circ} \mathrm{C}, 30 \mathrm{~s}$ of annealing $\left(65^{\circ} \mathrm{C}\right.$ for the primary $\beta$-giardin PCR and $55^{\circ} \mathrm{C}$ for the nested PCR), and $60 \mathrm{~s}$ at $70{ }^{\circ} \mathrm{C}$, with a final extension of $7 \mathrm{~min}$ at $72{ }^{\circ} \mathrm{C}$.

A 432-bp fragment of the $G d h$ gene was amplified using semi-nested PCR, as described by Read et al. [29]. In the primary PCR reaction, the DNA fragment was amplified using forward primer $\mathrm{GDHeF}$ and reverse primer GDHiR. In the sequential semi-nested PCR reaction, a 432-bp fragment was amplified using forward primer GDHiF and reverse primer GDHiR. In all cases, the PCR mixture consisted of $1 \times$ buffer containing $2 \mathrm{mM} \mathrm{MgCl}, 200 \mu \mathrm{M}$ of each dNTP (GC:TA = 3:1), 12.5 pmol of each primer, 1 unit of Taq DNA polymerase (Invitrogen), and $1 \mu$ of purified DNA in a final volume of $25 \mu \mathrm{l}$ for the primary PCR and $50 \mu \mathrm{l}$ for the snPCR. The PCR reactions were performed as follows: an initial denaturation step of $5 \mathrm{~min}$ at $94^{\circ} \mathrm{C}$, followed by 40 cycles consisting of $30 \mathrm{~s}$ at $94{ }^{\circ} \mathrm{C}, 20 \mathrm{~s}$ of annealing at $65^{\circ} \mathrm{C}$, and $45 \mathrm{~s}$ at $72^{\circ} \mathrm{C}$, with a final extension of $7 \mathrm{~min}$ at $72^{\circ} \mathrm{C}$. The PCR products were analyzed by electrophoresis on ethidium bromide-stained $1 \%$ agarose gels.

\subsection{Statistical analysis}

The data were analyzed using SPSS 19 software for Windows, with statistical analyses performed with the GraphPad Instat program (GraphPad Software, Inc., San Diego, California, USA). The chi-squared $\left(\chi^{2}\right)$ test was used to compare the frequency of enteroparasites in each children group. A probability $<0.05$ was considered significant.

The performance of the diagnostic tests for Giardia duodenalis was evaluated by calculating the sensitivity, specificity, positive predictive value (PPV), negative predictive value (NPV), and accuracy kappa coefficient using two different approaches, as described above.

\section{Results}

\subsection{Frequency of Giardia and other parasitic infections in children}

Of the children examined, 30.3\% (250/824) were found to be infected, with a predominance of monoparasitism in all groups. The cancer patients showed a high frequency of intestinal parasites (47.1\%), followed by the day-care (35.4\%), diarrheic (16.6\%), and malnourished (15.5\%) pediatric groups, as shown in Table 1. Protozoa infections were more frequent among the parasitized children.

Among the pathogenic parasites diagnosed, there was a higher occurrence of $G$. duodenalis infection (18.4\%), followed by Blastocystis hominis (5.3\%), Cryptosporidium sp. (1.9\%), Ascaris lumbricoides (1.9\%), Trichuris trichiura (1.6\%), and Entamoeba histolytica (0.8\%) (Table 1). Cryptosporidium sp. samples were diagnosed considering all positive results (modified Ziehl-Neelsen and/or ELISA). Of the 16 cases, 12 (75.0\%) were detected by both methods: two (12.5\%) were exclusively diagnosed by ELISA and another two (12.5\%) only by microscopy. The stool samples positive for the Entamoeba histolytica/dispar complex, as diagnosed by microscopy, from the cancer patients and day-care children were not confirmed by an ELISA specific for E. histolytica diagnosis. However, ELISA did identify seven diarrheal stool samples (five from the group with diarrheal disease and two from the malnourished children) as positive for Entamoeba histolytica. It is noteworthy that all seven samples positive for $E$. histolytica were diarrheic, including those from the patients with malnutrition.

In the children with cancer, the parasites Blastocystis hominis and Endolimax nana were found more frequently (11.4\%), followed by Giardia duodenalis (8.6\%). The opportunistic protozoan Cryptosporidium sp. was identified in the stool samples of two children (2.9\%). Among the malnourished children with enteroparasite infection, G. duodenalis (6.4\%) and then Cryptosporidium sp. (3.6\%) were the more common intestinal parasites found in fecal samples (Table 1). The protozoan Isospora belli was found only in this latter group. However, as this coccidian infection is most often related to AIDS, HIV serology was

Table 1

Frequency of Giardia and other parasitic infections in different groups of children.

\begin{tabular}{|c|c|c|c|c|c|}
\hline & \multicolumn{4}{|l|}{ Groups of children } & \multirow[t]{2}{*}{ Total $(\mathrm{n}=824)$} \\
\hline & Cancer $(\mathrm{n}=70)$ & Malnourished $(\mathrm{n}=110)$ & Diarrhea $(\mathrm{n}=151)$ & Day-care $(\mathrm{n}=493)$ & \\
\hline \multicolumn{6}{|l|}{ Gender - n [\% (95\%CI)] } \\
\hline Female & $32[45.7(33.9-58.0)]$ & $60[54.5(44.8-64)]^{\mathrm{a}}$ & $56[37.1(29.5-45.4)]^{\mathrm{ab}}$ & $235[47.7(43.2-52.2)]^{\mathrm{b}}$ & $383[46.5(43-50)]$ \\
\hline Male & $38[54.3(42.0-66.1)]$ & $50[45.5(36-55.2)]$ & $95[62.9(54.6-70.5)]$ & $258[52.3(47.8-56.8)]$ & $441[53.5(50-57)]$ \\
\hline \multicolumn{6}{|c|}{ Parasitism - n [\% (95\%CI)] } \\
\hline Monoparasitism & $20[28.6(18.7-40.8)]^{\mathrm{ab}}$ & $14[12.7(7.4-20.8)]^{\mathrm{ac}}$ & $19[12.6(7.9-19.2)]^{\mathrm{bd}}$ & $145[29.4(25.5-33.7)]^{\mathrm{cd}}$ & $198[24.0(21.2-27.1)]$ \\
\hline Biparasitism & $8[11.4(5.4-21.8)]^{\mathrm{abc}}$ & $2[1.8(0.3-7.1)]^{\mathrm{a}}$ & $4[2.6(0.9-7.1)]^{\mathrm{b}}$ & $22[4.5(2.9-6.8)]^{\mathrm{c}}$ & $36[4.4(3.1-6.1)]$ \\
\hline Polyparasitism & $5[7.1(2.7-16.6)]^{a}$ & $1[0.9(0.0-5.7)]$ & $2[1.3(0.2-5.2)]$ & $8[1.6(0.8-3.3)]^{\mathrm{a}}$ & $16[1.9(1.2-3.2)]$ \\
\hline Total & $33[47.1(35.2-59.4)]^{\mathrm{ab}}$ & $17[15.5(9.5-23.9)]^{\mathrm{ac}}$ & $25[16.6(11.2-23.7)]^{\mathrm{bd}}$ & $175[35.5(31.3-39.9)]^{\mathrm{cd}}$ & $250[30.3(27.2-33.6)]$ \\
\hline \multicolumn{6}{|c|}{ Specific enteroparasite infections (\%) } \\
\hline \multicolumn{6}{|c|}{ Protozoan } \\
\hline Giardia duodenalis & $6[8.6(3.5-18.4)]^{\mathrm{a}}$ & $7[6.4(2.8-13.1)]^{\mathrm{b}}$ & $5[3.3(1.2-8.0)]^{\mathrm{C}}$ & $134[27.2(23.3-31.4)]^{\mathrm{abc}}$ & $152[18.4(15.9-21.3)]$ \\
\hline Blastocystis hominis & $8[11.4(5.4-21.8)]^{\mathrm{a}}$ & $2[1.8(0.3-7.1)]^{\mathrm{a}}$ & $9[6.0(2.9-11.4)]$ & $25[5.1(3.4-7.5)]$ & $44[5.3(3.9-7.2)]$ \\
\hline Endolimax nana & $8[11.4(5.4-21.8)]^{\mathrm{abc}}$ & $2[1.8(0.3-7.1)]^{\mathrm{a}}$ & $2[1.3(0.2-5.2)]^{\mathrm{b}}$ & $19[3.9(2.4-6.1)]^{\mathrm{c}}$ & $31[3.8(2.6-5.4)]$ \\
\hline Entamoeba coli & $5[7.1(2.7-16.6)]^{\mathrm{a}}$ & $1[0.9(0.0-5.7)]$ & $1[0.7(0.0-4.2)]^{\mathrm{a}}$ & $17[3.4(2.1-5.6)]$ & $24[2.9(1.9-4.4)]$ \\
\hline Cryptosporidium sp & $2[2.9(0.5-10.9)]$ & $4[3.6(1.2-9.6)]^{\mathrm{a}}$ & $7[4.6(2.0-9.7)]^{\mathrm{b}}$ & $3[0.6(0.2-1.9)]^{\mathrm{ab}}$ & $16[1.9(1.2-3.2)]$ \\
\hline E. histolytica/dispar* & $5[7.1(2.7-16.6)]^{\mathrm{a}}$ & $2[1.8(0.3-7.1)]$ & $5[3.3(1.2-8.0)]^{\mathrm{b}}$ & $1[0.2(0.0-1.3)]^{\mathrm{ab}}$ & $13[1.6(0.9-2.8)]$ \\
\hline E. histolytica** & 0 & $2[1.8(0.3-7.1)]$ & $5[3.3(1.2-8.0)]$ & 0 & $7[0.8(0.4-1.8)]$ \\
\hline Iodamoeba butschlii & $2[2.9(0.5-10.9)]$ & 0 & 0 & 0 & $2[0.2(0.0-1.0)]$ \\
\hline Chilomastix mesnili & $1[1.4(0.1-8.8)]$ & 0 & 0 & 0 & $1[0.1(0.0-0.8)]$ \\
\hline Isospora belli & 0 & $1[0.9(0.0-5.7)]$ & 0 & 0 & $1[0.1(0.0-0.8)]$ \\
\hline \multicolumn{6}{|l|}{ Helminths } \\
\hline Ascaris lumbricoides & $5[7.1(2.7-16.6)]$ & $1[0.9(0.0-5.7)]$ & $2[1.3(0.2-5.2)]$ & $8[1.6(0.8-3.3)]$ & $16[1.9(1.2-3.2)]$ \\
\hline Trichuris trichiura & $2[2.9(0.5-10.9)]$ & $1[0.9(0.0-5.7)]$ & $2[1.3(0.2-5.2)]$ & $8[1.6(0.8-3.3)]$ & $13[1.6(0.9-2.8)]$ \\
\hline Hookworm & $5[7.1(2.7-16.6)]$ & 0 & 0 & 0 & $5[0.6(0.2-1.5)]$ \\
\hline Hymenolepis nana & $2[2.9(0.5-10.9)]$ & 0 & 0 & 0 & $2[0.2(0.0-1.0)]$ \\
\hline
\end{tabular}

${ }_{\mathrm{a}, \mathrm{b}, \mathrm{c}, \mathrm{d}}$ Equal letters indicate statistically significant differences $\left(P<0.05, \chi^{2}\right.$ test $)$ in the frequency of parasites among the groups of children.

* Positivity for the Entamoeba histolytica/E. dispar complex considering both parasitological and ELISA methods.

** Positive samples for Entamoeba histolytica confirmed by ELISA 
requested for this specific child, leading to a positive diagnosis. Based on the distribution of intestinal parasites among the inpatient children with diarrheal illness, such as the groups described above, the more common parasites diagnosed were Blastocystis hominis (6\%), Cryptosporidium sp. (4.6\%), Giardia duodenalis (3.3\%), and Entamoeba histolytica (3.3\%) (Table 1).

Statistically significant differences were observed when comparing the frequency of each protozoan among the groups. Giardia duodenalis was more frequent in the day-care group and Cryptosporidium sp. in children with diarrhea and malnutrition. In contrast, infections by Entamoeba histolytica were found only in the children with diarrhea (Table 1).

\subsection{Comparison between microscopy and ELISA for the diagnosis of G. duodenalis infection}

In the present study, we detected the presence of $G$. duodenalis in $152(18.4 \%)$ stool samples, making it the most common parasite among the 824 children examined. Considering the importance of identifying this parasite in children, we evaluated the concordance between the diagnostic techniques for Giardia in 796 fecal samples, as 28 samples were insufficient for performing ELISA. Among the 152 Giardia-positive samples, four were identified only by microscopy, 68 were identified by ELISA, and 80 were diagnosed by both techniques (Table 2). Notably, all of the Giardia-positive samples from the children hospitalized with diarrhea $(\mathrm{n}=5$ ) were only detected by ELISA (Table 2 ).

Samples with discordant immunologic and microscopic diagnosis results were reexamined twice by each method. In addition, all fecal samples with an optical density (OD) in ELISA between the cut-off $(\mathrm{OD}=0.09$ ), as established by the manufacturer, and up to 0.300 were retested by ELISA three times.

Considering microscopy as the gold standard for the diagnosis of giardiasis in all the children studied, ELISA showed a sensitivity of $95 \%$ and a specificity of $90 \%$. When considering all the positive samples as those identified by at least one of the diagnostic methods used, these values increased to $97 \%$ and $100 \%$, respectively (Table 3). For the combination of the two methods, only ELISA showed an efficiency of 99\% and a concordance that was considered excellent $(K>0.92)$. The individual analysis of pediatric groups showed the same pattern of rates as observed in the total group of children, with a lower sensitivity, efficiency, and kappa coefficient for microscopy (data not shown).

To examine the discrepancies observed between the results of microscopy and ELISA, 71 stool samples from day-care children with different patterns of Giardia positivity, according to the diagnostic method used, were randomly selected for PCR analysis. A sample was considered to be PCR-positive with amplification of the $\beta$-giardin and/ or Gdh gene. Of the three samples positive for Giardia only by microscopy, one was positive by PCR. In addition, 11 of 20 samples (55\%) diagnosed only by ELISA revealed a DNA band corresponding to the presence of $G$. duodenalis. Agreement of positivity between microscopy and ELISA occurred in $48 / 71$ (67.6\%) samples, with $43 / 48$ (89.6\%) confirmed by PCR (Fig. 1).

Table 2

Concordance of the results between diagnostic methods used for Giardia duodenalis identification in feces from children.

\begin{tabular}{llllll}
\hline \multicolumn{7}{c}{ Groups of children (positives/total) } \\
\cline { 2 - 6 } & $\begin{array}{l}\text { Cancer } \\
(6 / 70)\end{array}$ & $\begin{array}{l}\text { Malnourished } \\
(7 / 98)\end{array}$ & $\begin{array}{l}\text { Diarrhea } \\
(5 / 135)\end{array}$ & $\begin{array}{l}\text { Day care } \\
(134 / 493)\end{array}$ & $\begin{array}{l}\text { Total } \\
(152 / 796)\end{array}$ \\
\hline $\mathrm{N}(\%)$ of Giardia duodenalis-positive samples & & & \\
Microscopy & $0(0.0)$ & $1(14.3)$ & $0(0.0)$ & $3(2.2)$ & $4(2.6)$ \\
ELISA & $2(33.3)$ & $4(57.1)$ & $5(100.0)$ & $57(42.5)$ & $68(44.7)$ \\
Microscopy & $4(66.7)$ & $2(28.6)$ & $0(0.0)$ & $74(55.2)$ & $80(52.6)$ \\
and ELISA & & & & & \\
\hline
\end{tabular}

Table 3

Sensitivity, specificity, positive predictive value, negative predictive value, accuracy, and kappa coefficient (efficiency) of ELISA and microscopy for Giardia duodenalis diagnosis using fecal samples from children.

\begin{tabular}{llllllll}
\hline $\begin{array}{l}\text { Tested } \\
\text { method }\end{array}$ & Reference method & Sens. & Spec. & VPP & VPN & Kappa & Accur. \\
\hline ELISA & Microscopy & $95 \%$ & $90 \%$ & $54 \%$ & $99 \%$ & 0.64 & $90.9 \%$ \\
ELISA & $\begin{array}{l}\text { Microscopy and/or } \\
\text { ELISA }\end{array}$ & $97 \%$ & $100 \%$ & $100 \%$ & $98 \%$ & 0.98 & $99.5 \%$ \\
Microscopy & Microscopy and/or & $55 \%$ & $100 \%$ & $100 \%$ & $90 \%$ & 0.67 & $91.5 \%$ \\
& ELISA & & & & & & \\
\hline
\end{tabular}

Sens - Sensitivity; Spec - Specificity; PPV - positive predictive value; NPV - negative predictive value; Accur - Accuracy (efficiency).

\section{Discussion}

Intestinal parasites are spread heterogeneously in Brazil, with a frequency that varies according to the socioeconomic and clinical conditions, hygiene habits, and age of the population. Studies in Brazil have reported a frequency ranging between $5 \%$ and 94\% [30-32]. In the present study, $30.3 \%$ of the children examined were positive for one or more intestinal parasites. The high frequency of children infected by Giardia duodenalis and other protozoa observed in this study may be in part explained by the small size of cysts, which facilitates their passage through filters, and their resistance to the standard processes of water treatment $[33,34]$. Moreover, G. duodenalis often generates asymptomatic infections, thus favoring transmission from person to person [34].

In the group of children with cancer, we observed a frequency of intestinal parasites of $47.1 \%$, similar to other studies [18,35] and higher than the frequency reported for children with leukemia in South Brazil [36]; this can be explained by the higher socioeconomic development in relation to the Northeast. Regarding the specific occurrence of parasites in this group, the occurrence of B. hominis (11.4\%) and G. duodenalis (8.6\%) is noteworthy. Other studies have found a high incidence of $B$. hominis in patients with hematologic cancer [18,35-37], which may be related to the immunosuppressive effects of chemoprophylaxis and the opportunistic nature of this parasite [37].

In contrast to the group of neoplastic children, the group of children hospitalized due to severe protein-energy malnutrition exhibited the lowest frequency of intestinal parasites (15.5\%). This group was more frequently infected by $G$. duodenalis and Cryptosporidium sp., which may be due to the greater susceptibility to these parasites of patients with impaired immune response, including those with severe malnutrition $[38,39]$.

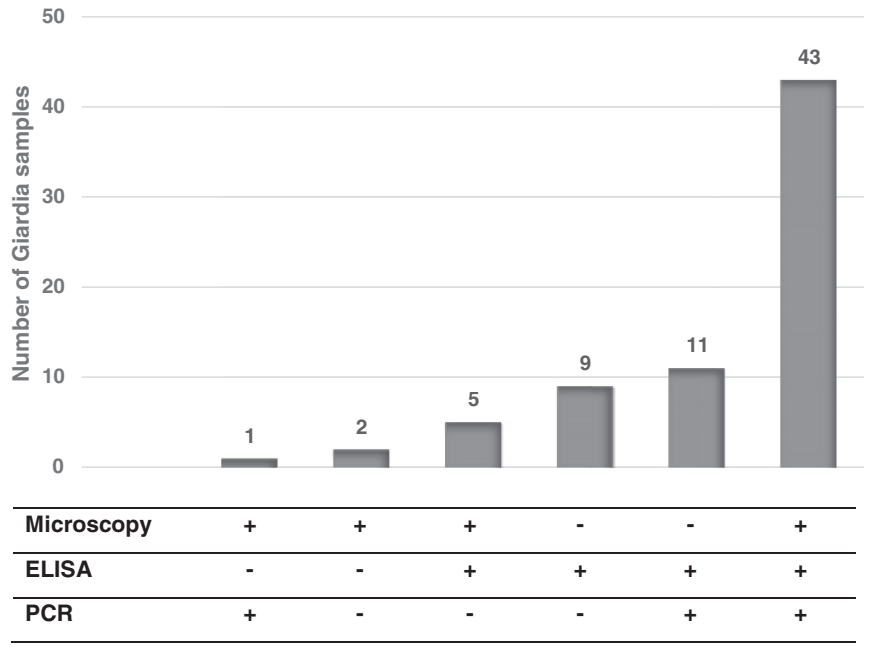

Fig. 1. Agreement between microscopy, ELISA, and PCR for Giardia duodenalis detection in 71 positive stool samples. 
With regard to day-care children, some studies in Brazil have reported a high prevalence of intestinal parasites, varying from $29.2 \%$ to $53.4 \%$ $[23,31,40]$. In the present study, we found an occurrence of parasitized children of $35.5 \%$, significantly higher than the group with diarrhea (16.6\%) or malnutrition (15.5\%). This high rate of parasitic infection may be associated with the ease of microorganism spread in day-care centers. The most common protozoan found in day-care children was G. duodenalis (27.2\%), corroborating data reporting significant rates of the parasite (between 5\% and 29\%) in children up to five years of age [41-44].

The distribution of intestinal parasites among children hospitalized with diarrhea showed the presence of Blastocystis hominis, Cryptosporidium sp., Giardia duodenalis, and Entamoeba histolytica. The last three protozoa are well described in the literature as causative agents of diarrhea in children and are always found in greater frequency in this group [20, 45]. Conversely, the relationship between Blastocystis hominis and diarrhea remains controversial: this agent was initially considered to be a commensal parasite, but it is now being accepted as a causative agent of diarrhea [46,47]. It is noteworthy that all E. histolytica-positive samples were diarrheal, including the sample from the patient with malnutrition. This diagnosis was only possible using a commercial ELISA kit specific for the species of parasite because microscopic examination does not allow for differentiation between E. histolytica and E. dispar [48].

It is notable that the concordance between ELISA and microscopy for Cryptosporidium diagnosis showed a considerable agreement, with discordant results in only 4/16 (25.0\%) cases. As ELISA has previously been able to diagnosis those Cryptosporidium species more often infecting humans (C. hominis and C. parvum) $[49,50]$, we suppose that the differences observed between ELISA and microscopy are not related to the species of Cryptosporidium but rather to the inherent limitations of both diagnostic methods.

Microscopic analysis is based on the morphological characteristics of the parasite, and its reliability is directly related to the experience of the sample observer. Moreover, the diagnostic efficiency for Giardia can be increased when three samples are examined instead of one [11]. As ELISA may be able to detect a minimal quantity of antigens, it can provide a positive result even when the parasitic load is low or a single sample is examined. The GIARDIA II test (Techlab), which was designed for use with both formed and diarrheal samples, detects an antigen produced during the encystment stage of the life cycle of the organism that is present in both encysting trophozoites and cysts. This test has been used in several studies for Giardia diagnosis using human fecal samples, including analyses with genotype characterization; the results showed that the test can detect equally the two major Giardia genotypes that infect humans, assemblages A and B [51,52]. Taking into consideration the possible failures that can occur with microscopic examination as well as the huge discrepancy compared to ELISA results, we chose to calculate the sensitivity, specificity, and other indexes using two different approaches. When using microscopy as the reference standard, ELISA had a sensitivity of $95 \%$ and a specificity of $90 \%$, values similar to those found in related studies $[13,53]$. When considering as the reference standard the combination of results of all the methods used, the ELISA specificity and PPV reached $100 \%$ and sensitivity $97 \%$, with excellent agreement (0.98) and an efficiency above 99\%. These results emphasize the variation in the performance of diagnostic techniques for giardiasis due to the choice of reference standard and consequently the need for better standardization. Indeed, Weitzel et al. [54] questioned microscopic detection as a reference standard in studies comparing parasite diagnostic techniques because of the impossibility of standardization, with a performance that is significantly influenced by the individual skill of the examiner and dependent on the parasite density.

Due to the discrepancies found between morphological identification by microscopy and antigen detection by ELISA, some positive samples were subjected to molecular biology analysis; for this, positive samples identified by both or only one of the diagnostic methods were selected. Forty-three (89.6\%) of 48 samples with concordant results were confirmed by PCR. Although PCR presented good agreement with the previous diagnostic technique, the results also emphasized the limitations of the molecular diagnosis of giardiasis, which has been observed in other studies $[16,55,56]$. PCR false-negative results have been attributed to difficulties in the extraction of parasite DNA, DNA degradation or mutations, and the presence of DNA polymerase inhibitors in feces that prevent amplification of the target gene [57-59].

Among the three microscopy-positive samples, one was confirmed by PCR, demonstrating that ELISA can also produce false-negative results. Some reports have correlated this failure to molecular changes in the antigen, such as degradation, lack of accessibility to the antibody site for reaction, or insufficient homogenization of the sample, resulting in the absence of antigen in the portion tested [60-62]. Finally, of the 20 samples detected only by ELISA, 55\% showed DNA amplification compatible with the presence of $G$. duodenalis. Although this result confirms the occurrence of positive samples by ELISA with negative results by microscopic examination, it also raises the possibility that $45 \%$ of the samples not confirmed by PCR were in fact ELISA false-positive results. Strand et al. [62] found 21 samples to be positive by ELISA but negative upon microscopic examination and associated them with newly eliminated infections, with a lack of whole parasite in the feces and only fragments and metabolic products. It is also unlikely that the high number of positive results by ELISA is the result of cross-reaction because most children showed no co-infection with other parasites. Testing an ELISA kit for the detection of G. duodenalis, Schunk et al. [53] reported the absence of false-positive results caused by other protozoa or helminths tested, including Blastocystis hominis, Entamoeba coli, Endolimax nana, and Ascaris lumbricoides.

Our findings showed that ELISA exhibits greater sensitivity than microscopic methods for Giardia diagnosis when analyzing a single sample. Additionally, ELISA allows for the simultaneous analysis of many samples, and the results are not dependent on technician expertise. Despite these advantages, the higher costs compared to parasitological methods difficult the use of ELISA for all patients in laboratory routine, especially in public heathy facilities. However, due to the high sensitivity and specificity of ELISA, this diagnostic approach would be very useful in pediatric hospitals and reference laboratories, particularly regarding children with diarrheal disease and in cases where there is a strong suspicion of giardiasis and patients have inconclusive or microscopy-negative results. Additionally, in developing countries, low-income individuals usually complain of difficulties in delivering more than one sample to the laboratory, which hampers the analysis of multiple stools and in turn affects the sensitivity of microscopy analyses.

\section{Acknowledgments}

This work was supported by the Fundação de Amparo à Pesquisa do Estado da Bahia (FAPESB) (APR0228/2008), Conselho Nacional de Desenvolvimento Científico e Tecnológico (CNPq/MCT) and Universidade Federal da Bahia (UFBA), Brazil.

\section{References}

[1] M.M. Nesti, M. Goldbaum, Infectious diseases and daycare and preschool education, J. Pediatr. 83 (4) (2007) 299-312.

[2] K. Papier, G.M. Williams, R. Luceres-Catubig, F. Ahmed, R.M. Olveda, D.P. McManus, D. Chy, T.N. Chau, D.J. Gray, A.G. Ross, Childhood malnutrition and parasitic helminth interactions, Clin. Infect. Dis. 59 (2) (2014) 234-243.

[3] D.A. Yones, L.A. Galal, A.M. Abdallah, K.S. Zaghlol, Effect of enteric parasitic infection on serum trace elements and nutritional status in upper Egyptian children, Trop. Parasitol. 5 (1) (2015) 29-35.

[4] L. Savioli, H. Smith, A. Thompson, Giardia and Cryptosporidium join the 'neglected diseases initiative', Trends Parasitol. 22 (5) (2006) 203-208.

[5] R.C. Thompson, The zoonotic significance and molecular epidemiology of Giardia and giardiasis, Vet. Parasitol. 126 (1) (2004) 15-35.

[6] R.C. Thompson, Giardiasis as a re-emerging infectious disease and its zoonotic potential, Int. J. Parasitol. 30 (12) (2000) 1259-1267. 
[7] E.C. Faust, W. Sawitz, J. Tobie, V. Odom, C. Peres, D.R. Lincicome, Comparative efficiency of various technics for the diagnosis of protozoa and helminths in feces, J. Parasitol. 25 (1) (1938) 241-262.

[8] F.T.F. Pacheco, R.K.N.R. Silva, A.S. Martins, R.R. Oliveira, N.M. Alcântara-Neves, M.P. Silva, et al., Differences in the detection of Cryptosporidium and Isospora (Cystoisospora) oocysts according to the fecal concentration or staining method used in a clinical laboratory, J. Parasitol. 99 (6) (2013) 1002-1008.

[9] D.T. John, W.A. Petri, Markell and Voge's Medical Parasitology, 9th ed Saunders Elsevier, Noida India, 2009.

[10] Clinical and Laboratory Standard Institute (CLSI), Procedures for the recovery and identification of parasites from the intestinal tract, 2. ed., 2005 (Pennsylvania).

[11] R.A. Hiatt, E.K. Markell, E. Ng, How many stool examinations are necessary to detect pathogenic intestinal protozoa? Am.J.Trop. Med. Hyg. 53 (1) (1995) 36-39.

[12] C.P. Cartwright, Utility of multiple-stool-specimen ova and parasite examinations in a high-prevalence setting, J. Clin. Microbiol. 37 (8) (1999) 2408-2411.

[13] C. Rodríguez-Ulloa, M. Rivera-Jacinto, ELISA and spontaneous sedimentation technique for the diagnosis of Giardia lamblia infection in stool samples of Peruvian children, Salud Publica Mex. 53 (6) (2011) 516-519.

[14] F.D. Al, S. Kustimur, T. Ozekinci, N. Balaban, M.N. Ilhan, The use of enzyme linked immunosorbent assay (ELISA) and direct fluorescent antibody (DFA) methods for diagnosis of Giardia intestinalis, Turkiye Parazitol. Derg. 30 (4) (2006) 275-278.

[15] C.F. Amar, P.H. Dear, S. Pedraza-Díaz, N. Looker, J. McLauchlin, Sensitive PCR-restriction fragment length polymorphism assay for detection and genotyping of Giardia duodenalis in human feces, J. Clin. Microbiol. 40 (2) (2002) 446-452.

[16] I. Bertrand, L. Albertini, J. Schwartzbrod, Comparison of two target genes for detection and genotyping of Giardia lamblia in human feces by PCR and PCR-restriction fragment length polymorphism, J. Clin. Microbiol. 43 (12) (2005) 5940-5944.

[17] S.M. Cacciò, U. Ryan, Molecular epidemiology of giardiasis, Mol. Biochem. Parasitol. 160 (2) (2008) 75-80.

[18] B.S. Menon, M.S. Abdullah, F. Mahamud, B. Singh, Intestinal parasites in Malaysian children with cancer, J. Trop. Pediatr. 45 (4) (1999) 241-242.

[19] J.H. Botero-Garcés, G.M. García-Montoya, D. Grisales-Patiño, D.C. Aguirre-Acevedo, M.C. Alvarez-Uribe, Giardia intestinalis and nutritional status in children participating in the complementary nutrition program, Antioquia, Colombia, May to October 2006, Rev. Inst. Med. Trop. Sao Paulo 51 (3) (2009) 155-162.

[20] F.A. Carvalho-Costa, A.Q. Gonçalves, S.L. Lassance, C.P. Albuquerque, J.P.G. Leite, M.N Boia, Detection of Cryptosporidium spp and other intestinal parasites in children with acute diarrhea and severe dehydration in Rio de Janeiro, Rev. Soc. Bras. Med. Trop. 40 (3) (2007) 346-348.

[21] P. Ferreira, M.R. Lima, F.B. Oliveira, M.L.M. Pereira, L.B.M. Ramos, M.G. Marçal, J.M. Costa-Cruz, Ocorrência de parasitas e comensais intestinais em crianças de escola localizada em assentamento de sem-terras em Campo Florido, Minas Gerais, Brasil, Rev. Soc. Bras. Med. Trop. 36 (1) (2003) 109-111.

[22] A.M.C. Monteiro, E.F. Silva, K.S. Almeida, J.J.N. Sousa, L.A. Mathias, F. Baptista, F.L.C. Freitas, Parasitoses intestinais em crianças de creches públicas localizadas em bairros periféricos do município de Coari, Amazonas, Brasil, Rev. Patol. Trop. 38 (4) (2010) 284-290.

[23] R.L. Lander, A.G. Lander, L. Houghton, S.M. Williams, H. Costa-Ribeiro, D.L. Barreto, et al., Factors influencing growth and intestinal parasitic infections in preschoolers attending philanthropic daycare centers in Salvador, Northeast Region of Brazil, Cad. Saude Publica 28 (11) (2012) 2177-2188.

[24] R.G. Moraes, Contribuição para o estudo do Strongyloides stercoralis e da estrongiloidose no Brasil, Rev. Serv. Espec. Saúde Pública 1 (1) (1948) 507-624.

[25] E.J. Inês, J.N. Souza, R.C. Santos, E.S. Souza, F.L. Santos, M.L.S. Silva, et al., Efficacy of parasitological methods for the diagnosis of Strongyloides stercoralis and hookworm in faecal specimens, Acta Trop. 120 (3) (2011) 206-210.

[26] S.A. Henriksen, J.F. Pohlenz, Staining of cryptosporidia by a modified Ziehl-Neelsen technique, Acta Vet. Scand. 22 (1) (1981) 594-596.

[27] S.M. Cacciò, M. Giacomo, E. Pozio, Sequence analysis of the beta-giardin gene and development of a polymerase chain reaction-restriction fragment length polymorphism assay to genotype Giardia duodenalis cysts from human faecal samples, Int. J. Parasitol. 32 (8) (2002) 1023-1030.

[28] M. Lalle, E. Pozio, G. Capelli, F. Bruschi, D. Crotti, S.M. Cacciò, Genetic heterogeneity at the beta-giardin locus among human and animal isolates of Giardia duodenalis and identification of potentially zoonotic subgenotypes, Int. J. Parasitol. 35 (2) (2005) 207-213.

[29] C.M. Read, P.T. Monis, R.C. Thompson, Discrimination of all genotypes of Giardia duodenalis at the glutamate dehydrogenase locus using PCR-RFLP, Infect. Genet. Evol. 4 (2) (2004) 125-130.

[30] M.L. Barreto, B. Genser, A. Strina, M.G. Teixeira, A.M. Assis, R.F. Rego, et al., Impact of a citywide sanitation program in Northeast Brazil on intestinal parasites infection in young children, Environ. Health Perspect. 118 (11) (2010) 1637-1642.

[31] A.L.R. Gonçalves, T.L. Belizário, J.B. Pimentel, M.P.A. Penatti, R.S. Pedroso, Prevalence of intestinal parasites in preschool children in the region of Uberlândia, State of Minas Gerais, Brazil, Rev. Soc. Bras. Med. Trop. 44 (2) (2011) 191-193.

[32] M.T.L. Seixas, J.N. Souza, R.P. Souza, M.C.A. Teixeira, N.M. Soares, Avaliação da frequência de parasitos intestinais e do estado nutricional em escolares de uma área periurbana de Salvador, Bahia, Brasil, Rev. Patol. Trop. 40 (4) (2011) 304-314.

[33] R.D. Newman, S.R. Moore, A.A. Lima, J.P. Nataro, R.L. Guerrant, C.L. Sears, A longitudinal study of Giardia lamblia infection in northeast Brazilian children, Tropical Med. Int. Health 6 (8) (2001) 624-634.

[34] C.K. Santos, D.F. Grama, J.E. Limongi, F.C. Costa, T.R. Couto, R.M. Soares, et al., Epidemiological, parasitological and molecular aspects of Giardia duodenalis infection in children attending public daycare centers in southeastern Brazil, Trans. R. Soc. Trop. Med. Hyg. 106 (8) (2012) 473-479.
[35] U. Aksoy, A. Erbay, C. Akisu, H. Apa, S. Ozkoç, S. Ozturk, Intestinal parasites in children with neoplasms, Turk. J. Pediatr. 45 (2) (2003) 129-132.

[36] C. Gabe, D.R. Almeida, L.O. Siqueira, Avaliação de eventos infecciosos oportunistas em crianças portadoras de leucemias, Rev. Bras. Hematol. Hemoter. 31 (2) (2009) 74-79.

[37] Y. Tasova, B. Sahin, S. Koltas, S. Paydas, Clinical significance and frequency of Blastocystis hominis in Turkish patients with hematological malignancy, Acta Med. Okayama 54 (3) (2000) 133-136.

[38] D. Mondal, J. Minak, M. Alam, Y. Liu, J. Dai, P. Korpe, et al., Contribution of enteric infection, altered intestinal barrier function, and maternal malnutrition to infant malnutrition in Bangladesh, Clin. Infect. Dis. 54 (2) (2012) 185-192.

[39] M.J.H. Rytter, L. Kolte, A. Briend, H. Friis, V.B. Christensen, The immune system in children with malnutrition - a systematic review, PLoS One 9 (8) (2014), e105017.

[40] T.T. Carvalho-Almeida, P.L.S. Pito, S.M.S. Quadros, D.M.A.G.V. Torres, H.Y. Kanamura A.M. Casimiro, Detection of Cryptosporidium sp. in non diarrheal faeces from children, in a day care center in the city of São Paulo, Rev. Braz. Inst. Med. Trop. S. Paulo 48 (1) (2006) 27-32.

[41] G.R. Ferreira, C.F. Andrade, Some socioeconomic aspects related to intestinal parasitosis and evaluation of an educational intervention in scholars from Estiva Gerbi, SP, Rev. Soc. Bras. Med. Trop. 38 (5) (2005) 402-405.

[42] A.L. Menezes, V.M.P. Lima, M.T.S. Freitas, M.O. Rocha, E.F. Silva, S.S. Dolabella, Prevalence of intestinal parasites in children from public daycare centers in the city of Belo Horizonte, Minas Gerais, Brazil, Rev. Inst. Med. Trop. S. Paulo 50 (8) (2008) 57-59.

[43] R.R. Silva, C.A. Silva, C.A.J. Pereira, R.L.C. Nicolato, D. Negrão-Corrêa, J.A. Lamounier et al., Association between nutritional status, environmental and socio-economic factors and Giardia lamblia infections among children aged 6-71 months in Brazil, Trans. R. Soc. Trop. Med. Hyg. 103 (5) (2009) 512-519.

[44] J.C. Teixeira, L. Heller, M.L. Barreto, Giardia duodenalis infection: risk factors for children living in sub-standard settlements in Brazil, Cad. Saude Publica 23 (6) (2007) 1489-1493.

[45] M.G. Pereira, E.R. Atwill, A.P. Barbosa, Prevalence and associated risk factors for Giardia lamblia infection among children hospitalized for diarrhea in Goiânia, Goiás State, Brazil, Rev. Inst. Med. Trop. Sao Paulo 49 (3) (2007) 139-145.

[46] A.M. El-Shazly, A.A. Abdeal-Magied, S.N. El-Beshbishi, H.A. El-Nahas, M.A. Fouad M.S. Monib, Blastocystis hominis among symptomatic and asymptomatic individuals in Talkha Center, Dakahlia Governorate, Egypt, J. Egypt. Soc. Parasitol. 35 (2) (2005) 653-666.

[47] E.C. Dinleyici, M. Eren, N. Dogan, S. Reyhanioglu, Z.A. Yargic, Y. Vandenplas, Clinical efficacy of Saccharomyces boulardii or metronidazole in symptomatic children with Blastocystis hominis infection, Parasitol. Res. 108 (3) (2011) 541-545.

[48] F.L. Santos, M.S. Gonçalves, N.M. Soares, Validation and utilization of PCR for differential diagnosis and prevalence determination of Entamoeba histolytica/Entamoeba dispar in Salvador City, Brazil, Braz. J. Infect. Dis. 15 (2) (2011) 119-125.

[49] S.E. Stroup, S. Roy, J. Mchele, V. Maro, S. Ntabaguzi, A. Siddique, G. Kang, R.L. Guerrant, B.D. Kirkpatrick, R. Fayer, J. Herbein, H. Ward, R. Haque, E.R. Houpt, Real-time PCR detection and speciation of Cryptosporidium infection using Scorpion probes, J. Microbiol. 55 (9) (2006) 1217-1222.

[50] J. Siwila, I.G. Phiri, J. Vercruysse, F. Goma, S. Gabriel, E. Claerebout, T. Geurden, Asymptomatic cryptosporidiosis in Zambian dairy farm workers and their household members, Trans. R. Soc. Trop. Med. Hyg. 101 (7) (2007) 733-734.

[51] O. Franzén, J. Jerlström-Hultqvist, E. Castro, E. Sherwood, J. Ankarklev, D.S. Reiner, D. Palm, J.O. Andersson, B. Andersson, S.G. Svärd, Draft genome sequencing of Giardia intestinalis assemblage B isolate GS: is human giardiasis caused by two different species? PLoS Pathog. 5 (8) (2009), e1000560.

[52] M. Alam, M. Ilias, A. Siddique, M. Kabir, F. Nazib, G.M. Khan, Genotype-specific detection of Giardia lamblia in stool samples of diarrhoeal and non-diarrhoeal patients in Dhaka, Bangladesh, Dhaka Univ. J. Biol. Sci. 20 (2) (2011) 183-189.

[53] M. Schunk, T. Jeline, K. Wetzel, H.D. Nothdurft, Detection of Giardia lamblia and Entamoeba histolytica in stool samples by two enzyme immunoassays, Eur. J. Clin. Microbiol. Infect. Dis. 20 (6) (2001) 389-391.

[54] T. Weitzel, S. Dittric, I. Mohl, E. Adusu, T. Jelinek, Evaluation of seven commercial antigen detection tests for Giardia and Cryptosporidium in stool samples, Clin. Microbiol. Infect. 12 (7) (2006) 656-659.

[55] A.J. Asher, L.S. Waldron, M.L. Power, Evaluation of a PCR protocol for sensitive detection of Giardia intestinalis in human faeces, Parasitol. Res. 110 (2) (2012) 853-858.

[56] S.H. Elsafi, T.N. Al-Magati, M.I. Hussein, A.A. Adam, M.M. Hassan, E.M. Al Zahrani, Comparison of microscopy, rapid immunoassay, and molecular techniques for the detection of Giardia lamblia and Cryptosporidium parvum, Parasitol. Res. 112 (4) (2013) 1641-1646.

[57] S. Oikarinen, S. Tauriainen, H. Viskari, O. Simell, M. Knip, PCR inhibition in stool samples in relation to age of infants, J. Clin. Virol. 44 (3) (2009) 211-221.

[58] C. Schrader, A. Schielke, L. Ellerbroek, R. Johne, PCR inhibitors: occurrence, properties and removal, J. Appl. Microbiol. 113 (5) (2012) 1014-1026.

[59] Y. Hawash, DNA extraction from protozoan oocysts/cysts in feces for diagnostic PCR Korean J. Parasitol. 52 (3) (2014) 263-271.

[60] T. Regnath, T. Klemm, R. Ignatius, Rapid and accurate detection of Giardia lamblia and Cryptosporidium spp. antigens in human fecal specimens by new commercially available qualitative immunochromatographic assays, Eur. J. Clin. Microbiol. Infect. Dis. 25 (12) (2006) 807-809.

[61] J.E. Rosenblatt, L.M. Sloan, S.K. Schneider, Evaluation of an enzyme-linked immunosorbent assay for the detection of Giardia lamblia in stool specimens, Diagn. Microbiol. Infect. Dis. 16 (4) (1993) 337-341.

[62] E.A. Strand, L.J. Robertson, K. Hanevik, J.O. Alvsvag, K. Mørch, N. Langeland, Sensitivity of a Giardia antigen test in persistent giardiasis following an extensive outbreak, Eur. Soc. Clin. Microbiol. Infect. Dis. 14 (11) (2008) 1065-1086. 